\title{
Study of causes and complications of intra uterine fetal death (IUFD)
}

\author{
Swapnil Patel, Rajal Thaker*, Parul Shah, Siddhartha Majumder
}

Department of Obstetrics \& Gynaecology, Smt N H L Municipal Medical College, Sheth V S General Hospital, Ahmedabad-380009, Gujarat, India

Received: 28 August 2014

Accepted: 19 September 2014

*Correspondence:

Dr. Rajal Thaker,

E-mail: rajalthaker@gmail.com

Copyright: (C) the author(s), publisher and licensee Medip Academy. This is an open-access article distributed under the terms of the Creative Commons Attribution Non-Commercial License, which permits unrestricted non-commercial use, distribution, and reproduction in any medium, provided the original work is properly cited.

\section{ABSTRACT}

Background: Intra Uterine Fetal Death (IUFD) is tragic event for the parents and obstetrician. Identification of causes of IUFD will be helpful in counseling of parents as well as for formulating preventive measures. Objectives of current study were to study the causes of Intra Uterine Fetal Death (IUFD), associated complications and to suggest preventive measures.

Methods: Study design: retrospective observational study. This study was carried out over a period of 3 months (April2014- June 2014) at a tertiary care hospital. Inclusion criteria was all IUFD > 20 weeks of gestation.

Results: Out of 1850 total births during the study period 80 IUFD occurred. Hence proportion of IUFD was $4.3 \%$. In our study, Still Birth Rate (SBR) as per WHO criteria (28 weeks) was 22.1 per 1000. Registered patients were 24 $(30 \%)$ whereas $56(70 \%)$ were emergency admissions. Majority of cases, $48(60 \%)$ were multigravidae with past obstetric history of abortion and IUFD in $13(16.2 \%)$ and $9(11.2 \%)$ respectively. In 31 (38.7\%) no identifiable cause of IUFD was found whereas cause was identified in $49(61.3 \%)$. IUFD occurred in $27(33.7 \%)$ cases of PIH and eclampsia, out of them abruptio placenta was present in $10(12.5 \%)$. Other causes of IUFD were anemia, oligoamnios, fever, congenital anomaly, cord accidents and jaundice in 9 (11.2\%), $5(6.2 \%), 3(3.7 \%), 2(2.5 \%), 2(2.5 \%)$ and 1 (1.2\%) respectively. Vaginal delivery occurred in $73(91.2 \%)$ and $7(8.7 \%)$ required surgical intervention. Most common complication associated with IUFD was Disseminated Intravascular Coagulation (DIC) in 18 (22.5\%) followed by Sepsis in 8 (10\%), Acute Renal Failure (ARF) in 3 (3.7\%), Maternal mortality in $1(1.2 \%)$.

Conclusions: Anemia, PIH, accidental haemorrhage were leading causes of IUFD. Majority of women who had IUFD were emergency admission who had not received adequate antenatal care. A significant proportion of IUFD is preventable by health education to patients and community for regular antenatal care, about warning signs during antenatal period, hospital delivery and early referral.

Keywords: Intra uterine fetal death (IUFD)

\section{INTRODUCTION}

IUFD is a traumatic event both for mother and her family. According to $\mathrm{WHO}^{1}$ Intra uterine fetal death (IUFD) is defined as,

"Death prior to expulsion or extraction of a product of human conception from its mother, irrespective of duration of pregnancy and which is not an induced termination of pregnancy, death indicated by fact that after such separation fetus does not show any evidence of life such as beating of heart, pulsation of cord, or definite movement of voluntary muscles. Heartbeats are to be distinguished from transient cardiac contraction; respirations are to be distinguished from fleeting respiratory effort or gasps".

The definition of a stillbirth varies across countries. In the United States, reporting requirements for IUFD determined by each state and thus, requirements differ 
significantly. Most states require reporting of fetal death at 20 weeks gestation or a minimum 350 grams birthweight. Three states require reporting of fetal deaths with birthweight 500 gram or more roughly equivalent to 22 weeks. $^{1}$

This study was carried out in tertiary care hospital to identify the causes of IUFD, to study maternal complications in IUFD and to suggest possible preventive measures to decrease the further incidence of IUFD.

\section{METHODS}

This retrospective observational study was carried out from April 2014 - June 2014 at a tertiary care hospital where not only patients from urban area but also patients from nearby rural areas and adjoining states come for treatment.

Analysis of case records of patients having IUFD was done as per emergency or registered admission, age, parity, past obstetric history, cause of IUFD, mode of delivery, laboratory investigations, maternal complications and blood transfusion details. Inclusion criteria of IUFD were gestational age 20 weeks or more.

\section{RESULTS}

As shown in Table 1 there were $56(70 \%)$ emergency and $24(30 \%)$ registered admissions. Among them 65 (81.2\%) were between age group of 21-30 years, 1 (1.2\%) was 43 year old patient.

Majority of cases, $48(60 \%)$ were multigravidae with past obstetric history of abortion and IUFD in 13 (16.2\%) and $9(11.2 \%)$ respectively.

Table 1: Maternal characteristics.

\begin{tabular}{|c|c|c|}
\hline Details $(\mathrm{N}=\mathbf{8 0})$ & Number & Percentage (\%) \\
\hline \multicolumn{3}{|c|}{ Type of admission } \\
\hline Emergency & 56 & 70 \\
\hline Registered & 24 & 30 \\
\hline \multicolumn{3}{|l|}{ Age } \\
\hline$<20$ years & 14 & 17.5 \\
\hline $21-25$ years & 35 & 43.7 \\
\hline 26-30 years & 30 & 37.5 \\
\hline$>35$ years & 1 & 1.25 \\
\hline \multicolumn{3}{|l|}{ Parity } \\
\hline Primigravida & 32 & 40 \\
\hline Multigravida & 48 & 60 \\
\hline \multicolumn{3}{|c|}{ Past obstetric history } \\
\hline H/o abortion & 13 & 16.2 \\
\hline H/o IUFD & 9 & 11.2 \\
\hline
\end{tabular}

As shown in Table 2, IUFD occurred in $>28$ weeks of gestational age were 41 giving SBR of 22/1000 total births.
Table 2: Weeks of pregnancy at the time of admission.

\begin{tabular}{lll|}
$\begin{array}{l}\text { Weeks of } \\
\text { pregnancy } \\
(\mathbf{N}=80)\end{array}$ & Number & Percentage \\
\hline $20-24$ & 18 & 22.5 \\
\hline $25-28$ & 21 & 30 \\
\hline $29-32$ & 29 & 36.2 \\
\hline $33-36$ & 8 & 10 \\
\hline 37 or more & 4 & 5 \\
\hline
\end{tabular}

As per shown in Table 3, in $31(38.7 \%)$ no identifiable cause of IUFD was found. IUFD occurred in 27 (33.7\%) cases of PIH and eclampsia, out of them abruptio placenta was present in $10(12.5 \%)$. Other causes of IUFD were anemia, oligoamnios, fever, congenital anomaly, cord accidents and jaundice in 9 (11.2\%), 5 $(6.2 \%), 3(3.7 \%), 2(2.5 \%), 2(2.5 \%)$ and $1(1.2 \%)$ respectively.

Table 3: Causes of IUFD.

\begin{tabular}{|c|c|c|}
\hline Causes of IUFD ( $\mathrm{N}=\mathbf{8 0})$ & Number & Percentage \\
\hline Unexplained & 31 & 38.7 \\
\hline PIH (Pre-eclampsia + eclampsia) & 27 & 33.7 \\
\hline Anemia & 9 & 11.2 \\
\hline Oligoamnios & 5 & 6.2 \\
\hline Fever & 3 & 3.7 \\
\hline Congenital anomaly & 2 & 2.5 \\
\hline Cord accidents & 2 & 2.5 \\
\hline Jaundice & 1 & 1.2 \\
\hline
\end{tabular}

As shown in Table 4, $73(91.2 \%)$ delivered vaginally, 4 $(5 \%)$ required caesarean section and $3(3.7 \%)$ required hysterotomy.

Table 4: Mode of delivery.

\begin{tabular}{|lll|}
\hline Mode of delivery $(\mathrm{N}=80)$ & Number & Percentage \\
\hline Normal vaginal delivery & 73 & 91.2 \\
\hline Caesarean section & 4 & 5 \\
\hline Hysterotomy & 3 & 3.7 \\
\hline
\end{tabular}

As shown in Table 5, DIC was present in $18(22.5 \%)$, sepsis in $8(10 \%)$, Acute Renal Failure (ARF) occurred in $3(3.7 \%)$ cases of abruptio placenta which was managed by hemodialysis. Maternal mortality occurred in 1 $(1.2 \%)$.

Table 5: Maternal complications.

\begin{tabular}{|lll|}
\hline Maternal complications $(\mathrm{N}=80)$ & Number & Percentage \\
\hline $\begin{array}{l}\text { Disseminated intravascular } \\
\text { coagulation (DIC) }\end{array}$ & 18 & 22.5 \\
\hline Sepsis & 8 & 10 \\
\hline Acute renal failure (ARF) & 3 & 3.7 \\
\hline Maternal mortality & 1 & 1.2 \\
\hline
\end{tabular}


As shown in Table 6, 15 (18.7\%) required transfusion of PCV. Blood components were given in the form of FFP, PRC and cryoprecipitate in 18 (22.5\%), 16 (20\%) and 18 $(22.5 \%)$ cases respectively. In most cases more than one components given to patient.

Table 6: Transfusion of blood components.

\begin{tabular}{|lll|}
\hline Blood components & Number & Percentage \\
\hline Packed cell volume (PCV) & 15 & 18.7 \\
\hline Fresh frozen plasma (FFP) & 18 & 22.5 \\
\hline Platelet rich concentrate (PRC) & 16 & 20 \\
\hline Cryoprecipitate & 18 & 22.5 \\
\hline
\end{tabular}

\section{DISCUSSION}

In many low-income and middle-income countries, counting stillbirths is a challenge. Systems to monitor pregnancies and to register births and deaths are weak. ${ }^{2}$ So for international comparisons, $\mathrm{WHO}^{3}$ considers stillbirths as pregnancy losses at or after 28 weeks of pregnancy, or a birth-weight of at least $1000 \mathrm{~g}$. worldwide, the stillbirth rate (SBR) has declined from 22.1 stillbirths per 1000 births in 1995 to 18.9 stillbirths per 1000 births in $2009 .^{4}$

During the study period there were 80 IUFD out of 1850 total birth hence proportion of IUFD in our study $(>20$ weeks) was 43 per 1000 total birth, but as per WHO criteria (>28 weeks) SBR in our study was 22.2 which is almost same as SBR of India, that is $22^{2}$.

In present study, incidence of IUFD was higher among 56 (70\%) emergency admissions compared to 24 (30\%) registered admissions. Korde $\mathrm{NV}$ et al. ${ }^{5}$ and Anjali $\mathrm{C}$ et al. ${ }^{6}$ reported a higher SBR in emergency admissions as $84.9 \%$ and $89.5 \%$ respectively. Kameshwaran et al. ${ }^{7}$ observed five times higher stillbirth rate in emergency cases. Lack of inadequate antenatal care (ANC) is the most important problem that needs urgent attention. If patient have taken adequate ANC then complication like anemia, PIH etc. can be diagnosed at earlier stage and managed. So, IUFD due to these causes can be prevented. It is a well-established fact that adequate ANC is associated with better pregnancy outcome. ${ }^{8}$ Al Kadri et $\mathrm{al}^{9}$ found that women who did not receive ANC are at $70 \%$ risk of IUFD.

In present study $5(6.2 \%)$ were 19 years of age, 35 $(43.7 \%)$ were between age of 21-25 years, and elderly primi $1(1.2 \%)$. Showghy et al. stated that pregnancy at the age of 16 years and less then increase the IUFD risk factor 4 times. ${ }^{10}$ Frett et al. has concluded that age of 35 and more can increase risk of fetal death at the rate of 1.5 times. ${ }^{11}$

The parity of the patient influences pregnancy outcome. In present study proportion of IUFD was higher in multigravida $48(60 \%)$. Korde-NV et al. ${ }^{5}$ observed $51.6 \%$ of multigravida who had stillbirths.
In our study, $22(27.5 \%)$ had a past history of reproductive loss in the form of abortion 13 (16.2\%) and history of IUFD 9 (11.2\%). Past obstetric history of pregnancy loss has chances of recurrence if the previous loss is due to Antiphospholipid Antibody Syndrome (APS). ${ }^{12}$ Diagnosed case of APS should treated with low dose of aspirin and low molecular weight heparin, as APS is responsible for recurrent early first trimester abortion early onset severe pre-eclampsia and severe placental insufficiency resulting in premature delivery or IUFD.

Prematurity and Intra Uterine Growth Restriction (IUGR) is another risk factor for fetal death. In present study, 50 $(62.5 \%)$ were between $25-32$ weeks of gestational age. Chitra K et al. $^{13}$ reported $57.8 \%$ of IUFD who were preterm. Al Kadri et al. ${ }^{9}$ reported ten fold increase risk of IUFD in patients having IUGR. Pregnancy losses associated with placental insufficiency and preterm labor are more likely to recur. ${ }^{14}$

In present study, unexplained IUFD occurred in 31 $(38.7 \%)$ compared to $33 \%$ reported by Neetu Singh et al. $^{15}$

In the present study, PIH and eclampsia together accounted for $27(33.7 \%)$ cases of IUFD. Abruptio placenta due to PIH accounted for 10 (12.5\%). Anjali C et al. $^{6}$ reported PIH causes IUFD in $30 \%$ and abruptio placenta in $10.4 \%$. Korde-NV et al. ${ }^{5}$ reported the most common cause for IUFD was abruptio placenta $21.9 \%$ and PIH-eclampsia together accounted for $18.7 \%$. In the study by Kumar et al. ${ }^{16} \mathrm{PIH}$ was the most common cause of IUFD in $19 \%$ and accidental haemorrhage in $9.8 \%$. Al Kadri et al. ${ }^{9}$ reported 25 and 3 fold increases risk of IUFD in patients having PIH and abruptio placenta. Antepartum hemorrhage leads to maternal blood loss leading to hypovolemia, anemia, hypoxia, hypertonic uterine contraction causing fetal hypoxia and death. In $\mathrm{PIH}$, vasospasm decreases blood flow to all organs particularly uteroplacental perfusion so oxygen supply to fetus decreases and leads to fetal hypoxia and IUFD.

In the present study, IUFD occurred due to Anemia in 9 (11.2\%) compared to $16 \%$ reported by Anjali C et al. ${ }^{6}$ IUFD due to anemia could be prevented by adequate antenatal care along with iron-folic acid supplementation. Iron deficiency is the most common cause of anaemia in pregnancy and iron and folic acid supplements are recommended for prevention. ${ }^{17}$

In present study, $2(2.5 \%)$ cases of congenital malformation of neural tube defect lead to IUFD. Anjali $\mathrm{C}$ et al. ${ }^{2}$ and Kumar et al. ${ }^{16}$ had reported IUFD due to congenital malformation in $10.5 \%$ and $10 \%$ respectively.

In the present study, cord accidents accounted for 2 $(2.5 \%)$ which were emergency admission presented with prolapsed cord. Korde NV et al. ${ }^{5}$ reported $5.2 \%$ cord accidents and all were emergency admissions. Anjali $\mathrm{C}$ et al. reported $1.9 \%$ cord accidents. ${ }^{6}$ 
In the present study, maternal infection of hepatitis $E$ lead to IUFD in $1(1.25 \%)$. HEV infection can be transmitted from mother to fetus and affect fetal outcome with higher incidence of stillbirths and neonatal deaths. ${ }^{18}$

In the present study, majority of the patients required induction with prostaglandins in the form of PGE1 tablet in $14(17.5 \%)$ and PGE2 gel in $32(40 \%)$. Augmentation of labor was done in $24(30 \%)$ patients who had good Bishops score, by oxytocin and artificial rupture of membranes. Spontaneous labor occurred in 10 (12.5\%).

In present study, normal vaginal delivery occurred in 73 $(91.2 \%)$ compared to Korde NV et al. ${ }^{5}$ and Chitra $\mathrm{K}$ et al. ${ }^{13}$ who had reported vaginal delivery in $73.1 \%$ and $89.4 \%$ respectively. Surgical intervention required in 7 $(8.7 \%)$. Caesarean section required in $4(5 \%)$ and hysterotomy in $3(3.7 \%)$. Indication for caesarean section was previous cesarean section with induction failure in two cases and previous cesarean section with severe abruptio placenta, previous 2 cesarean section. Hysterotomy done in one case of previous 3 cesarean section and 2 cases were induction failure.

Most common complication associated with IUFD was DIC that occurred in $18(22.5 \%)$ and all of them required transfusion of blood components. In most cases more than one component was given. Thormboplastins released from blood clots, damaged placenta and dead fetus activates coagulation cascade and that leads to DIC. These cases were managed by treatment of underlying condition and by maintaining perfusion to vital organs, transfusion of blood and blood components. Availability of multispeciality and intensive care helps in management of these patients.

Acute Renal Failure (ARF) was encountered in 3 (3.7\%) presented with abruptio placenta which were managed by hemodialysis. Septicemia was present in $8(10 \%)$ and managed by intravenous fluid and higher antibiotics. During this study period maternal mortality occurred in 1 (1.2\%) due to multiple organ dysfunction. This patient had come with abruptio placenta and developed ARF.

In the present study, one or more antenatal or intranatal factors which caused death of the fetus could be identified in more than $61.3 \%$ case compared to Korde $\mathrm{NV}$ et al. $^{5}$ cause of stillbirth identified in $81.2 \%$. Adequate antenatal and intranatal care along with timely admission to the hospital can help not only in prevention but management of severe anemia, PIH, jaundice and its complications.

\section{CONCLUSION}

Anaemia, PIH, accidental haemorrhage were leading causes of IUFD. Majority of women who had IUFD were emergency admission who had not received adequate antenatal care. A significant proportion of IUFD is preventable by health education to patients and community for regular antenatal care, about warning signs during antenatal period, hospital delivery and early referral.

\section{ACKNOWLEDGEMENTS}

We hereby would like to thank Dr. S. T. Malhan, the superintendent of Sheth V. S. general hospital, Dr. Pankaj R Patel, the dean of Smt N. H. L. municipal medical college to allow us to publish this paper.

Funding: No funding sources

Conflict of interest: None declared

Ethical approval: The study was approved by the institutional ethics committee

\section{REFERENCES}

1. F. Cunningham, Kenneth Leveno, Steven Bloom, Catherine Y. Spong, Jodi Dashe. Stillbirth. In: F. Cunningham, Kenneth Leveno, Steven Bloom, Catherine Y. Spong, Jodi Dashe, eds. Williams Obstetrics. 24th ed. New York: McGraw-Hill Professional; 2014: 661-666.

2. Lawn JE, Blencowe H, Pattinson R, Cousens S, Kumar R, Ibiebele I, et al. Stillbirths: Where? When? Why? How to make the data count? Lancet. 2011;377(9775):1448-63.

3. WHO. Stillbirths, 2014. Available at: www.who.int/maternal_child_adolescent/epidemiolo gy/stillbirth/en/. Accessed 16 August 2014.

4. Cousens S, Stanton C, Blencowe H, Chou D, Ahmed S, Steinhardt L, et al. National, regional, and worldwide estimates of stillbirth rates in 2009 with trends since 1995: a systematic analysis. Lancet. 2011 Apr;377(9774):1319-30.

5. Korde NV, Gaikwad P. Causes of stillbirth. J Obstet Gynaecol India. 2008;58(4):314-7.

6. Anjali C, Vineeta G. Epidemiology of Intrauterine fetal deaths: a study in tertiary referral center in Uttarakhand. IOSR J Dent Med Sci. 2014;13(3):036.

7. Kameshwaran C, Bhatia BD, Bhat BV, Oumachigui A. Perinatal mortality: a hospital based study. Indian Paediatr. 1993;30:997-1001.

8. Richardus, Jan H, Graafmans, Wilco C. The perinatal mortality rate as an indicator of quantity of care in international comparison. Med Care. 1998;36(1):5466.

9. Al Kadari, Hanan T, Hani. Factors contributing to intra uterine fetal death. Arch Obstet Gynaecol. 2012;286(5):1109.

10. Showghy S, Milaat W. Early teenage marriage and subsequent pregnancy outcome. East Mediterr Health J. 2000;6(1):46-53.

11. Fretts RC, Usher RH. Causes of fetal death in women of advanced maternal age. Obstet Gynaecol. 1997;89:40.

12. Rai R, Regan L. Antiphospholipid in pregnancy. Curr Obstet Gynaecol. 1998;8:32. 
13. Chitra K, Nitin N, Anuradha K, Anil S. Intrauterine fetal death: a prospective study. J Obstet Gynaecol India. 2001;51(5):94-7.

14. Silver RM. Fetal death. Obstet Gynaecol. 2007;109:153.

15. Neetu S, Kiran P, Neena G, Arya AK. A retrospective study of 296 cases of intrauterine fetal death at a tertiary care center. Int $\mathbf{J}$ Reprod Contracept Obstet Gynaecol. 2013;2(2):141-6.

16. WHO. Daily iron and folic acid supplementation in pregnant women. In: WHO, eds. WHO Guideline. Geneva: World Health Organization; 2012: 1-27.
17. Kumar RM, Devi A, Bhat V, Oumachigui A. Analysis of stillbirths in referral hospital. J Obstet Gynaecol India. 1996;46:791.

18. ACOG Practice Bulletin No 86. Viral hepatitis in pregnancy. ACOG Obstet Gynaecol. 2007;110(4):941-56.

DOI: $10.5455 / 2320-1770 . i j r \operatorname{cog} 20141211$

Cite this article as: Patel $\mathrm{S}$, Thaker R, Shah P, Majumder S. Study of causes and complications of intra uterine fetal death (IUFD). Int J Reprod Contracept Obstet Gynecol 2014;3:931-5. 